\title{
Tinzaparin Sodium
}

National Cancer Institute

\section{Source}

National Cancer Institute. Tinzaparin Sodium. NCI Thesaurus. Code C60810.

The sodium salt of a low molecular weight heparin (LMWH), obtained by controlled enzymatic depolymerization of heparin from porcine intestinal mucosa, with antithrombotic properties. Tinzaparin is a potent inhibitor of several activated coagulation factors, especially Factors Xa and IIa (thrombin); its primary activity is mediated through the plasma protease inhibitor antithrombin. In addition, this agent may inhibit angiogenesis through: 1) competitive binding of the heparin-binding sites on endothelial cells for the proang iogenic cytokines vascular endothelial growth factor (VEGF) and beta-fibroblast growth factor (beta-FGF) and 2) increasing the release of tissue factor pathway inhibitor (TFPI), a negative regulator of angiogenesis. 